\title{
Cardiologists' Knowledge and Attitudes About Methadone and Buprenorphine Maintenance Treatment: A Survey Study in Tehran, Iran
}

\author{
Arsia Taghva ${ }^{1}$; Farhad Amanolahi ${ }^{1}$; Alireza Khoshdel ${ }^{2}$; Mohammad Reza Kazemi ${ }^{1}$; Kamyab \\ Alizadeh ${ }^{2, *}$ \\ ${ }^{1}$ Disaster and Military Psychiatry Research Center, AJA University of Medical Sciences, Tehran, IR Iran \\ ${ }^{2}$ Department of Epidemiology, AJA University of Medical Sciences, Tehran, IR Iran \\ ${ }^{*}$ Corresponding author: Kamyab Alizadeh, Department of Epidemiology, AJA University of Medical Sciences, Tehran, IR Iran. Tel/Fax: +98-2139954937, E-mail: Kamyab_alizadeh@ \\ yahoo.com
}

Received: May 26, 2014; Revised: August 25, 2014; Accepted: September 15, 2014

\begin{abstract}
Background: Todays, methadone and buprenorphine maintaining treatment (MMT/BMT) is considered an effective method for opioiddependent patients. It seems that lack of enough information among health care specialists including cardiologists about such treatments could result in some problems for patients such as relapse into addiction.

Objectives: This study aimed to investigate knowledge and attitude of cardiologists in Tehran, Iran, about MMT/BMT for opioid-dependent patients with a clinical picture of acute coronary syndrome.

Materials and Methods: In a multicentric analytical-observational study on clinical cardiologists of five teaching hospitals in Tehran, knowledge and attitude about MMT/BMT in patients with cardiovascular complains were assessed by an investigator-made self-reported questionnaire.

Results: Of a hundred invitation contacts, 55 cardiologists participated in the study (missing rate of $45 \%$ ). The mean age of respondents was $42.23 \pm 3.13$ and $76.4 \%$ were female. Only $49.1 \%$ of cardiologists answered to all the five questions correctly and most (92.7\%) declared to have a little or moderate information about MMT/BMT.

Conclusions: It seems that physicians have low to moderate levels of knowledge regarding the treatment of patients receiving BMT/MMT. It is recommended to train physicians during some study courses about MMT/BMT to improve their knowledge in this field. Of course, participation in seminars and conferences about MMT/BMT can be another effective strategy to increase the level of awareness in health care professionals.
\end{abstract}

Keywords:Methadone; Buprenorphine; Healthcare Providers; Knowledge; Attitudes

\section{Background}

Treatment of drug-dependent patients with buprenorphine and methadone has become a successful method in developed countries leading to more acceptances of physicians to administer these life-saving medicines for their patients. Methadone is a synthetic opioid agonist with longtime agonistic activity at the mu-opioid receptors and is the most common drug used for the relief of withdrawal symptoms. Gradual reduction of the dosage of each drug can be used. Two advantages of methadone detoxification including the oral route of administration and its long acting effect make it superior to other methods as an appropriate therapy for opiate withdrawal treatment. Moreover, methadone is a safe drug for long-term use and only should be aware of the initial dosage $(1,2)$. Methadone and buprenorphine maintenance treatment (MMT/BMT) has the following benefits: 1) reducing illegal drug use; 2) stabilizing patient's life; 3) decreasing arbitrary use of drugs; 4) reducing criminal activities; 5) decreasing high-risk behaviors related to needle sharing; 6) reducing mortality and morbidity rates related to substances abuse; and
7) providing a normal social situations for patients $(3,4)$. Studies reported that quality of life of participants in MMT programs increased after three months of treatment (5-7). A study from Iran for a 6-month period on 46 patients taking either methadone or naltrexone showed that patients in methadone group had a better general health and social functioning (8). Initiation of MMT for patients with chronic conditions, such as cardiovascular diseases may make a great challenge for clinicians, especially cardiologists. On the other hand, complications related to drug overdose such as respiratory depression, circulatory depression, respiratory arrest, shock, cardiac arrest, QT interval prolongation, and potentially lethal cardiac arrhythmias necessitate careful management and monitoring to identify and correct undesirable side effects or adverse reactions, as well as unfavorable drug-drug interactions $(9,10)$. It is not surprising that cardiologists should be more up to date concerning approaches in this field. However, it seems that knowledge of specialists including cardiologists about MMT/ BMT especially for complicated patients is not sufficient,

Copyright ( 2014, Kowsar Corp.; Published by Kowsar. This is an open-access article distributed under the terms of the Creative Commons Attribution-NonCommercial 4.0 International License (http://creativecommons.org/licenses/by-nc/4.0/) which permits copy and redistribute the material just in noncommercial usages, provided the original work is properly cited. 
Taghva A et al.

because these patients are usually referred to a psychiatrist or even the therapeutic approach to these patients is associated with some caution and doubt. It causes some problems for patients, such as wasting time for the treatment leading to relapse into addiction.

\section{Objectives}

We aimed to investigate the knowledge and attitude of cardiologists in Tehran, Iran, about methadone and buprenorphine maintenance treatment for opioid dependent patients with a clinical picture of acute coronary syndrome.

\section{Materials and Methods}

A multicentric analytical-observational study was performed on clinical cardiologists of five teaching hospitals in Tehran including Imam-Khomeini, Tehran Heart Center, Imam-Reza, Imam-Hossein, and Be'sat Hospital between 2012 and 2013. The study was performed on a representative sample of cardiologists working in Tehran, Iran. All participants were randomly selected from a complete record list of cardiologists. To calculate the sample size, $\mathrm{N}=\mathrm{z2} \mathrm{p}$ (1-p)/ $\mathrm{d} 2$ formula was used; where $\mathrm{N}$ was the minimum required sample size; Z score was 1.96 for the confidence level 95\%; p as the proportion affected; and d, the desired precision of this expected proportion. The approximate prevalence of the problem was assumed 50\% (0.5) and its desired precision (d) was 0.1, then the minimum sample size was calculated as 96 . The study was approved by the research ethics committee of AJA University of Medical Sciences. We contacted 100 cardiologists, and all gave verbal or written consent to participate in the study. The sampling method used was simple sampling technique and the population was selected based on five mentioned teaching health centers in Tehran, Iran. Data was collected by self-reported questionnaires. Demographic characteristics, including age, graduation year, faculty member status, location of their clinics in Tehran, and history of visiting an opioid-dependent patient were assessed in all participants. We designed a 13-item questionnaire, an investigator-made questionnaire used for the study, which its validity and reliability were determined before data gathering. To confirm the validity of the questionnaire, we used content validity method and to confirm the reliability we used Cronbach's alpha test. The content validity of the questionnaire was tested by a panel of five expert psychologists. The final questionnaire was initially tested in a pilot study on 20 cardiologists and shown to be reliable with a Cronbach's alpha of 0.784. Two areas were defined for this study; knowledge questions and attitude questions about MMT/BMT in patients with cardiovascular complains. The knowledge was assessed with five three-option questions (yes/no/do not know), from which only one option was the correct answer. The attitude was evaluated with eight three-option questions. All statistical analyses were performed using SPSS, version 17 (SPSS, Chicago, Illinois). Data were presented as mean \pm SD for quantitative variables and frequency and percent for qualitative variables.

\section{Results}

Fifty-five cardiologists participated in the study and took back the questionnaires. The rate of missing data was $45 \%$. Table 1 summarized basic characteristics of the study population. There were 42 women $(76.4 \%)$ and the mean age of respondents was $42.23 \pm 3.13$ years. About a half of our study population (49.1\%) were in 40-50 years age group graduated between 1990 and 2000. Most cardiologists (78.2\%) were university faculty members and about $85.5 \%$ (47 cardiologists) had received post-graduate fellowship trainings. Location of the respondents' private clinic was distributed in four areas of Tehran including north (25.5\%), south (29.1\%), east (20\%), and west (25.2\%). Of the study subjects, 33 (60\%) had a history of visiting an opioid-dependent patient. Tables 2 and 3 showed the knowledge questions about MMT/BMT in a patient with cardiac disease and the number of correct responses by cardiologists. Only 27 respondents (49.1\%) answered to all the knowledge questions correctly. Table 4 showed the attitude and perception of cardiologists toward MMT/BMT in a patient with a cardiac disease. Only $7.3 \%$ of participants (4 subjects) stated to have a good knowledge and most (92.7\%) declared to have a little or moderate information about MMT/BMT. About 50.9\% of participants believed that a patient receiving MMT/BMT

\begin{tabular}{|c|c|}
\hline Variable & Results \\
\hline \multicolumn{2}{|l|}{ Gender } \\
\hline Men & $13(23.6)$ \\
\hline Women & $42(76.4)$ \\
\hline Age, y & $42.23 \pm 3.13$ \\
\hline \multicolumn{2}{|l|}{ Age category } \\
\hline 30-40 Years & $21(38.2)$ \\
\hline 40-50 Years & $27(49.1)$ \\
\hline 50-60 Years & $7(12.7)$ \\
\hline \multicolumn{2}{|c|}{ Faculty member } \\
\hline Yes & $43(78.2)$ \\
\hline No & $12(21.8)$ \\
\hline \multicolumn{2}{|c|}{ Graduation year } \\
\hline $1980-1990$ & $6(10.9)$ \\
\hline $1990-2000$ & $27(49.1)$ \\
\hline $2000-2010$ & $22(40)$ \\
\hline \multicolumn{2}{|c|}{ Post graduate (fellowship) courses } \\
\hline Yes & $47(85.5)$ \\
\hline No & $8(14.5)$ \\
\hline \multicolumn{2}{|c|}{ Clinic location in Tehran } \\
\hline North & $14(25.5)$ \\
\hline South & $16(29.1)$ \\
\hline East & $11(20)$ \\
\hline West & $14(25.2)$ \\
\hline \multicolumn{2}{|c|}{ History of visiting an opioid-dependent patient } \\
\hline Yes & $33(60)$ \\
\hline No & $22(40)$ \\
\hline
\end{tabular}


Taghva A et al.

with a cardiac problem never requires to be referred to a consulting psychiatrist. Besides, $20 \%$ of cardiologists stated that an opioid-dependent patient with cardiovascular problem should continue opioids and $14.5 \%$ of them had no decision for this patient. About 25.5\% stated that MMT/BMT causes changes in ECG of patients receiving these treatments compared to other people with a cardiac problem, while $23.6 \%$ had no information about this.

\begin{tabular}{|c|c|c|c|}
\hline \multirow[t]{2}{*}{ Knowledge Questions } & \multicolumn{3}{|c|}{ Response } \\
\hline & Yes & No & Do not know \\
\hline Does using opiates interfere in the treatment of cardiac disease? & $11(20)$ & $41(74.5)^{\mathrm{C}}$ & $3(5.5)$ \\
\hline Does MMT/BMT suppress symptoms resulting in development of patients' cardiac diseases? & $3(5.5)$ & $43(78.2)^{\mathrm{C}}$ & $9(16.4)$ \\
\hline Does MMT/BMT interfere with cardiac medications? & $3(5.5)$ & $\begin{array}{c}50 \\
(90.9)^{\mathrm{c}}\end{array}$ & $2(3.6)$ \\
\hline $\begin{array}{l}\text { Does methadone have stronger adverse effects than other opioids on cardiovascular sys- } \\
\text { tem? }\end{array}$ & $2(3.6)$ & $42(76.4)^{\mathrm{C}}$ & $11(20)$ \\
\hline Does MMT/BMT cause difficulty in the treatment of cardiac disease? & $4(7.3)$ & $37(67.3)^{\mathrm{C}}$ & $14(25.5)$ \\
\hline
\end{tabular}

\footnotetext{
a Abbreviations: MMT/BMT, methadone and buprenorphine maintaining treatment.

$\mathrm{b}_{\text {Data are presented as No. (\%). }}$

${ }^{\mathrm{C}}$ The correct response.
}

\begin{tabular}{lc}
\hline Table 3. Correct Responses to the Questions by Cardiologists & NO. (\%) \\
\hline Number of Correct Responses & $27(49.1)$ \\
\hline Five correct responses & $10(18.2)$ \\
Four correct responses & $8(14.5)$ \\
Three correct responses & $6(10.9)$ \\
Two correct responses & $2(3.6)$ \\
One correct response & $2(3.6)$ \\
None & \\
\hline
\end{tabular}

Table 4. Questions About Cardiologists' Attitude Toward MMT/BMT in a Patient With a Cardiac Disease a,b

\begin{tabular}{|c|c|c|c|}
\hline Attitude Questions & & Replies & \\
\hline $\begin{array}{l}\text { How much do you know about MMT/BMT in opioid-dependent } \\
\text { patients? }\end{array}$ & A little: $21(38.2)$ & Moderate: 30 (54.5) & Good: 4 (7.3) \\
\hline $\begin{array}{l}\text { Does a patient treated with } \mathrm{MMT} / \mathrm{BMT} \text { with a cardiac problem } \\
\text { require to be referred to a consulting psychiatrist? }\end{array}$ & Yes: $12(21.8)$ & Never: 28 (50.9) & $\begin{array}{l}\text { Depends on patient's } \\
\text { status: } 15(27.3)\end{array}$ \\
\hline $\begin{array}{l}\text { Can we start MMT/BMT for a patient who previously had used } \\
\text { opiates and now has a problem? }\end{array}$ & $\begin{array}{l}\text { MMT/BMT can be } \\
\text { started: } 36(65.5)\end{array}$ & $\begin{array}{l}\text { Opioids should be } \\
\text { continued: } 11(20)\end{array}$ & Don't know: 8 (14.5) \\
\hline $\begin{array}{l}\text { Does dealing with individuals treated with MMT/BMT differ } \\
\text { from normal population? }\end{array}$ & Yes: 6 (10.9) & No: $43(78.2)$ & Don’t know: 6 (10.9) \\
\hline $\begin{array}{l}\text { Have you ever visited a patient receiving MMT/BMT therapy } \\
\text { who had cardiac problems? }\end{array}$ & Yes: $26(47)$ & No: 28 (50.9) & $\begin{array}{l}\text { Yes/referred to other } \\
\text { physicians: } 1(1.8)\end{array}$ \\
\hline $\begin{array}{l}\text { Does prescription of cardiac medications reduce or increase } \\
\text { the amount of consumable methadone? }\end{array}$ & Yes: $3(5.5)$ & No: 45 (81.8) & Don't know: 7 (12.7) \\
\hline $\begin{array}{l}\text { Does MMT/BMT alter ECG of patients receiving these treatments } \\
\text { compared to ordinary people with cardiac problem? }\end{array}$ & Yes:14 (25.5) & No: $28(50.9)$ & Don't know: 13 (23.6) \\
\hline Does MMT/BMT affect patient prognosis in case of surgery? & Yes: 4 (7.3) & No: $30(45.5)$ & Don't know: 21 (38.2) \\
\hline
\end{tabular}

\footnotetext{
a Abbreviations: MMT/BMT, methadone and buprenorphine maintaining treatment.

${ }^{b}$ Data are presented as No. (\%).
} 


\section{Discussion}

In our study, most cardiologists stated to have a little or moderate information about MMT/BMT and about a half of them preferred to refer a patient receiving MMT/BMT to a psychiatrist, which could reflect their doubt and caution in this issue. Moreover, less than a half of our study participants answered to all five knowledge questions correctly. However, correct answers to these questions do not necessarily guarantee adequate information about MMT/BMT and correct or incorrect responses can only estimate experts' knowledge. Nevertheless, a wrong answer to each of these questions and inappropriate dealing with MMT/BMT patients may lead to irreparable damages to them. Our study was the first on cardiologists' awareness and attitude toward cardiovascular issues in MMT/BMT. Mcgillion et al. performed a study in London on 206 general practitioners (GPs) as the major part in the care and treatment of drug-dependent patients to assess their attitudes and knowledge towards the management of these patients (11). Similar to our study, less than a half of GPs felt to have adequate knowledge about opioid-dependent patients and stated to need training and educational courses. McKeown et al. in the UK conducted semi-structured telephone interviews on 48 GPs and concluded that they were becoming more confident and comfortable with drug dependent patients, and more positive towards MMT, but still felt to need necessary knowledge and skills (12). Krantz et al. conducted a study to assess physicians' awareness about cardiac effects of methadone by a national mail survey of physicians licensed as medical directors for accredited USA opioid treatment programs in 2006 (13). The primary outcome was knowledge of methadone QT-prolonging effects. Physicians $(n=692)$ included family practitioners (35\%), internists (25\%), psychiatrists (22\%), and self-identified as addiction specialists ( $8 \%$ ). They found that only $41 \%$ of respondents were aware of methadone QT-prolonging properties and concluded that scientific publication alone was inadequate in raising awareness regarding methadone QT-prolonging properties, even among those who often prescribe the medication (13). Our study and other similar researches showed that the level of physicians' awareness about treatment of drug-dependent patients including MMT and its related factors is inadequate. A study by Shen et al. in Taiwan suggested that education and training courses regarding harm reduction program in healthcare workers was important to increase the attitude toward MMT and related knowledge directly (14). Another study by Springer and Bruce in the USA on 27 individuals who worked directly with inmates found that a minority of respondents referred released prisoners with a history of opioid dependency for MMT/BMT. They stated that more education of individuals treating and caring HIV-infected opioid dependent prisoners was needed (15). A study by Caplehorn et al. was performed to measure changes in attitudes of staff working in public methadone programs in Sydney after an attempt had been made to change the aim of methadone treatment from abstinence to harm-minimization. They found no changes in staff's attitudes and knowledge of the risks and benefits of MMT. They suggested that problems with staff attitudes and indirectly, effectiveness of public health interventions could be addressed by educational campaigns (16). It seems that physicians have low to moderate level of knowledge regarding the treatment of patients receiving BMT/MMT. A high rate of missing data (45\%) from primary selected sample due to several excuses such as being busy or personal problems and some others, may affirm low level of awareness of these professionals towards this type of treatment, because they did not complete the questionnaires. On the other hand, it is important how they deal with problems in patients receiving MMT/BMT as a large population in some societies. Consequently, it is recommended to train physicians during their study courses about MMT/BMT to improve their knowledge in this field. Of course, participation in seminars and conferences about MMT/BMT can be another effective strategy to increase the level of awareness in health care professionals. It is suggested to perform further studies to evaluate the level of knowledge with greater sample size among other health care professionals and in a larger area in the country.

\section{Acknowledgements}

We appreciate all cardiologists who participated in this study.

\section{Authors' Contributions}

Study concept and design: Taghva, Amanolahi and Khoshdel; analysis and interpretation of data: Taghva and Alizadeh; drafting of the manuscript: Taghva; critical revision of the manuscript for important intellectual content: Taghva, Amanolahi, Khoshdel, Kazemi and Alizadeh; statistical analysis: Kazemi and Alizadeh.

\section{Funding/Support}

This study was supported financially by AJA University of Medical Sciences.

\section{References}

1. Sadock BJ, Sadock VA, Sussman N. Kaplan and Sadock s pocket handbook of psychiatric drug treatment.: Wolters Kluwer Health; 2005.

2. Connock M, Juarez-Garcia A, Jowett S, Frew E, Liu Z, Taylor RJ, et al. Methadone and buprenorphine for the management of opioid dependence: a systematic review and economic evaluation. Health Technol Assess. 2007;11(9):1-171.

3. Farnia M, Ebrahimi B, Shams A, Zamani S. Scaling up methadone maintenance treatment for opioid-dependent prisoners in Iran. Int J Drug Policy. 2010;21(5):422-4.

4. Noori R, Narenjiha H, Aghabakhshi H, Habibi G, Khoshkrood Mansoori B. Methadone maintenance therapy outcomes in Iran. Subst Use Misuse. 2012;47(7):767-73.

5. Giacomuzzi SM, Riemer Y, Ertl M, Kemmler G, Rossler H, Hinterhuber H, et al. Gender differences in health-related quality of life 


\section{Taghva A et al.}

on admission to a maintenance treatment program. Eur Addict Res. 2005;11(2):69-75.

6. Xiao L, Wu Z, Luo W, Wei X. Quality of life of outpatients in methadone maintenance treatment clinics. J Acquir Immune Defic Syndr. 2010;53 Suppl 1:S116-20.

7. Lashkaripour K, Bakhshani NM, Sadjadi SA. Quality of life in patients on methadone maintenance treatment: a three-month assessment. J Pak Med Assoc. 2012;62(10):1003-7.

8. Sayyah M, Sharifi M, Rokni P. Comparison of General Well-being of Patients Undergoing Methadone Maintenance Therapy(MMT) with Patients Undergoing Naltrexone Therapy. Iran J Public Health. 2013;42(2):145-8.

9. Haigney MC. First, do no harm: QT interval screening in methadone maintenance treatment. J Addict Dis. 2011;30(4):309-12.

10. Leal MA, January CT. Cardiovascular Effects of Methadone. Handbook of Methadone Prescribing and Buprenorphine Therapy:: Springer; 2013. pp. 51-8.

11. McGillion J, Wanigaratne S, Feinmann C, Godden T, Byrne A. GPs' attitudes towards the treatment of drug misusers. Br J Gen Pract. 2000;50(454):385-6.

12. McKeown A, Matheson C, Bond C. A qualitative study of GPs' attitudes to drug misusers and drug misuse services in primary care. Fam Pract. 2003;20(2):120-5.

13. Krantz MJ, Rowan SB, Schmittner J, Bucher Bartelson B. Physician awareness of the cardiac effects of methadone: results of a national survey. J Addict Dis. 2007;26(4):79-85.

14. Shen YM, Lin SR, Chen CL, Huang TM, Huang YH, See LC, et al. The dual pathway of professional attitude among health care workers serving HIV/AIDS patients and drug users. AIDS Care. 2013;25(3):309-16.

15. Springer SA, Bruce RD. A pilot survey of attitudes and knowledge about opioid substitution therapy for HIV-infected prisoners. $J$ Opioid Manag. 2008;4(2):81-6.

16. Caplehorn RM, Lumley TS, Irwig L, Saunders JB. Changing attitudes and beliefs of staff working in methadone maintenance programs. Aust N Z J Public Health. 1998;22(4):505-8. 